\title{
Editorial
}

\author{
Volume 11 Number 2, December 2012
}

\section{Malaysia needs more teaching hospitals}

Hospitals in Malaysia are divided into public and private; the latter category exceeds by nearly twice. Among the public hospitals, there are also divisions into specialist, state, and district, and overlapping with those being the teaching and non-teaching hospitals. Strictly speaking, there are only three teaching hospitals, each under a medical faculty or university with the fourth (IIUM) scheduled to start operation in 2016. Teaching hospitals are under the purview of the Ministry of Higher Education. The growth in undergraduate medical education over the last decade ${ }^{1}$ sees the expansion of a new kind of hospital used for teaching where large state or district public hospitals are affiliated with both public and private medical schools for teaching purposes in addition to service provision and research for the affiliated university staffs. In this case, previously service oriented hospitals are made to function like a teaching hospital. Despite many inherent limitations, this model, used by both public and private medical schools, has been relatively successful to allow public hospitals to be used for teaching undergraduate medicine. Nowadays, we are seeing this model being stretched even further to assume more roles traditionally associated with a teaching hospital with variable and limited success. For the purposes of this editorial however, hospitals extensively used for teaching as in this model are included under teaching hospital definition and there are at least another five of them.

A teaching hospital is a hospital that provides clinical education and training to doctors, nurses, and other health professionals, in addition to delivering medical care. Its affiliation with a medical school or university made it known alternatively as a university hospital. It is also strongly committed to research and is a center for clinical expertise, innovation and medical sub-specialization. For these multitudes of functions, a teaching hospital must be owned by a medical school or a university but in terms of clinical service provision, it may be part of a national health system.

Do we need more hospitals or hospital beds?

The simple answer is yes for hospital beds based on the bed to 10,000 people ratio. In Malaysia, it is only 18, 31 or thereabout in Singapore, Vietnam or USA, and as high as 137 in Japan, the country that tops the list. ${ }^{2}$ This somewhat relates to our position in the healthcare performance index at 49 and Singapore at 6th, granted that this index relies on other parameters too. ${ }^{3}$ But why we should not look at this need for more beds by expansion of the size of a hospital is the issue of congestion. Lack of hospital space overall would severely limit the capacity of an expansion to cater for the increased demand, it would create more problems than solve, examples would be the ensuing traffic congestion, limited parking space, demand on already stretched clinical services (e.g. pathology, radiology or allied health services) so on and so forth. Therefore, building new hospitals to increase hospital beds should be the answer to this.

Why we need to build teaching hospitals and not just hospitals?

There is not much data on public perception of our hospitals, nor have we ever ranked their performances on a national scale. Ranking as part of patient choice and empowerment is quite prevalent in developed countries and liked by politicians and the public, but less so by clinicians. Whether ranking actually influences the final choice is quite debatable as there are other factors to contend. In the US for example, for more than two decades, US News has been compiling a list of their best hospitals. ${ }^{4}$ Death rates, patient safety, and hospital reputation are a few of the factors considered and those honored are hospitals that scored near the top in at least six medical specialties. The honor list contains top 17 that are all teaching hospitals. In one study in the $90 \mathrm{~s}^{5}$ for example, it is not surprising therefore that the American public views teaching hospital as one precondition to quality health institution. We have no local ranking data to reflect on this, but it would be difficult to predict a different result in a survey of patient preference as the prevailing conditions are quite the same.

What else differentiates teaching hospitals from non-teaching hospitals? Again, I am unaware if anyone has done such comparison but let's briefly look at Pahang. ${ }^{6,7}$ The state general hospital (HTAA) and a few others are affiliated with the medical faculty of IIUM, and this has led to an increase in the number of research projects as measured by NMRR registration for Pahang (nearly three-quarters of total came from IIUM), the number and type of clinical sub-specialization services offered, and training courses including conferences conducted annually (53 compared to less than 15 by HTAA in 2010). In addition, unrelated to being a teaching hospital is the sponsorship of medical equipment and facilities, although never scientifically looked at, these changes are bound to increase the number and quality of health service delivery as a whole.

In Malaysia, another key difference is that teaching hospitals offer postgraduate medical courses in the form of Malaysian Qualifications Agency (MQA) 
approved Masters in Medicine (MMED) programs. These programs are instrumental in the training of general specialists in the country (more than $80 \%$ of our clinical staff is MMED trained), although subspecialization which may last for up to four years post MMED, by and large, takes place in nonteaching, in addition to teaching hospitals. For postgraduate medical training, MMED programs are very important as reliance on other postgraduate qualifications such as overseas college exams is increasingly becoming less reliable in light of major revision in postgraduate medical training in the their country of origin. In the UK's Modernizing Medical Career initiative for example, MRCP is no longer an entrance requirement for postgraduate training let alone to be considered as an exit examination for medical specialization, it is just a requirement in the quest to become a specialist in their chosen area where a satisfactory journey through the whole five year training program is far more important to test competency and performance, quite similar to our own MMED or the residency program in the US. There are ongoing efforts to facilitate similar suitable postgraduate college exams (like MRCP) to take place in this country, but the response is at best variable. The MMED program, however, has seen a more than $50 \%$ increase in intake to nearly 900 places although the recruitment process can be made better to allow better occupancy, this is excluding places for candidates with other public scholarships joining the program during the second annual intake. The need for more established medical schools to have a suitably sized teaching hospital of their own to support MMED programs is beyond question, because the requirements of postgraduate medical education are challenging and cutting edge. A mere coexistence in partnership in the present model, excluding the three teaching hospitals (UMMC, UKMMC and HUSM), is stretching the coexistence to the limit. A similar case can be made for undergraduate medical education but the success of the present model of partnership for more than 30 medical schools makes the case for undergraduate teaching and training less strong.

Malaysia needs more hospitals and the way forward is to build more teaching hospitals. IIUM teaching hospital project is a step in the right direction that will lead to an improvement in the healthcare delivery in the country.

\footnotetext{
Professor Dr Mohammed Fauzi Abdul Rani Dean, Kulliyyah of Medicine, International Islamic University Malaysia
}

\section{REFERENCES}

1. Fauzi ARM. The big business of undergradu ate medical training. International Medical Journal Malaysia 2012;11(1):1-3.

2. Health workforce, infrastructure and essential medicines. In: World health sta tistics 2012 [online]. Available at: http: // www.who.int/healthinfo/EN_ WHS2012_ Full.pdf. Accessed October 10, 2012.

3. The world health report 2000 - Health sy tems: improving performance. Available at: http://www.who.int/whr/2000en/in dex. html. Accessed October 9, 2012.

4. America's Best Hospitals report. In: U.S News \& World Report, Available at http: / / en.wikipedia.org/wiki/ U.S.News_\%26 World_Report. Accessed October 30, 2012.

5. Boscarino JA. The public perception of quality hospitals II: Implications for patient surveys. Hosp Health Serv Adm 1992;37(1):13-35.

6. Laporan Tahunan Hospital Tengku Ampuan Afzan 2010. MOH/P/PAH/75.10 (unpub lished)

7. Annual Report 2010. Kulliyyah of Medicine. International Islamic University Malaysia. (unpublished) 